\title{
BASEL II INTERNATIONAL CONVENTION: GENERAL RULES ON MARKET DISCIPLINE, DEMAND TO DISCLOSE INFORMATION
}

\author{
Marina V. Goncharova \\ Plekhanov Russian State University of Economics (Volgograd Branch), Volgograd, Russian Federation
}

Introduction: the article concludes the study of Basel II Agreement; the author examines the general requirements for commercial banks to comply with the market discipline. Structurally, the paper investigates the provisions of the Third pillar of Basel II (part IV of the Agreement); the pillar integrates the disciplinary rules in the banking market in the member countries of Basel II Agreement "International Convergence of Capital Measurement and Capital Standards: New Approaches", including the requirements for commercial banks on information disclosure. The purpose of the study is to examine the foundations of the discipline in the banking market and the content of the requirements for commercial banks on information disclosure. Methods: there are applied in conjunction the methods of scientific knowledge, including the basic methods of systematicity, analysis and the comparative law method. Results: it is proved that the submission of banks to the market discipline is the basis of forming the banking sector with low levels of risk and high level of reliability of the participants of the banking market. The need to ensure the safe and reliable functioning of this market legitimizes the requirement of the supervisory bodies for banks on information disclosure. Practically, the Third pillar of Basel II contains the requirements on information disclosure by the banks, which are enshrined in the form of 13 tables, paragraphs 822-826 of the Agreement. Each table provides for specific positions reflecting the disclosure by the bank of specific qualitative information and specified in the relevant table of specific quantitative information. Conclusions: the Third pillar of the "International Convergence of Capital Measurement and Capital Standards: New Approaches" of Basel II Agreement is entirely devoted to the market discipline; the provisions of the document provide for the powers and resources of the supervisory authorities to compel the banks to disclose information. The result of this disclosure becomes a qualifying criterion, based on which different methodologies are applied and the related banking transactions and tools are recognized. Basel II Agreement establishes a validation rule by the user and the need for expert evaluation by the user whether the information disclosed by the bank he is interested in is significant.

Key words: bank, risks, capital, adequacy, requirement, regulation, market, discipline.

УДК 341.161

ББК 67.39

\section{МЕЖДУНАРОДНОЕ СОГЛАШЕНИЕ БАЗЕЛЬ ІІ: ОБЩИЕ ПОЛОЖЕНИЯ О РЫНОЧНОЙ ДИСЦИПЛИНЕ, ТРЕБОВАНИЯ РАСКРЫТИЯ ИНФОРМАЦИИ Марина Вячеславовна Гончарова \\ Российский государственный экономический университет им. Г.В. Плеханова (Волгоградский филиал), г. Волгоград, Российская Федерация}




\section{МЕЖДУНАРОДНОЕ ПРАВО И СРАВНИТЕЛЬНОЕ ПРАВОВЕДЕНИЕ}

Введение: в статье завершается изучение Соглашения Базель II, автор рассматривает общие требования к коммерческим банкам по соблюдению рыночной дисциплины. Структурно в данной работе исследуются положения Третьего компонента Базеля II (часть IV Соглашения), данный компонент интегрирует в себе правила дисциплины на банковском рынке в странах - участницах Соглашения Базель II «Международная конвергенция измерения капитала и стандартов капитала: новые подходы», включая требования к коммерческим банкам о раскрытии информации. Цель исследования - рассмотреть основы дисциплины на банковском рынке и содержание требований к коммерческим банкам о раскрытии информации. Методы: применены в совокупности методы научного познания, среди которых основные - методы системности, анализа и сравнительно-правовой. Результаты: обосновано, что подчинение банков рыночной дисциплине является основой формирования банковской сферы с низкими уровнями рисков и высоким уровнем надежности участников рынка банковских продуктов и услуг. Необходимость обеспечения безопасного и надежного функционирования этого рынка легитимирует требование органов надзора к банкам о раскрытии информации. Практически Третий компонент Базеля II содержит требования к раскрытию банками информации, которые закреплены в виде 13 таблиц, в параграфах 822-826 Соглашения. Каждая таблица предусматривает конкретные позиции, отражающие раскрытие банком определенной качественной информации и указанной в соответствующей таблице конкретной количественной информации. Выводы: Третий компонент «Международной конвергенции измерения капитала и стандартов капитала: новые подходы» Соглашения Базель II целиком посвящен рыночной дисциплине, положения документа предусматривают полномочия и средства органов надзора принуждать банки к раскрытию информации. Результатом раскрытия информации становится квалификационный критерий, опираясь на который применяются те или иные методологии и признаются соответствующие банковские операции и инструменты. Соглашение Базель II закрепляет правило проверки пользователем и необходимость экспертной оценки самим пользователем того, считать ли информацию, раскрытую интересующим его банком, существенной.

Ключевые слова: банк, риски, капитал, достаточность, требование, регулирование, рынок, дисциплина.

\section{Введение}

Соглашение, известное в российской банковской практике и литературе как Базель I «Международная конвергенция измерения капитала и стандартов капитала» 1988 г. (Basel Capital Accord. International Convergence of Capital Measurement and Capital Standards), a также соглашение, развивающее Базель I, Соглашение Базель II «Международная конвергенция измерения капитала и стандартов капитала: новые подходы» [2] исследуются в рамках трехлетнего тематического цикла статей нашего журнала.

В составе Первого компонента Базеля II (в части II Соглашения) регламентируются технологии снижения кредитных рисков в рамках стандартизированного подхода. Этот первыц подход основывается на внешних оценках авторитетных рейтинговых агентств. Второй подход (также в части II Соглашения) в составе Первого компонента Базеля II предусматривает возможность использования банками для оценки кредитного риска собственных рейтинговых алгоритмов. Затем (также в части II Соглашения) в составе Первого компонента Базеля II регла- ментируются меры по нейтрализации кредитного риска на основе использования банками рамочного подхода секъюритизации. Далее - правила регулирования операционного риска. Завершается Первый компонент Базеля II (часть II Соглашения) положениями о порядке формирования и регулирования банком торгового портфеля как особого набора финансовых инструментов.

Завершая изучение Соглашения Базель II, рассмотрим далее общие требования к коммерческим банкам по соблюдению рыночной дисциплины. Уточним, что структурно здесь мы переходим к исследованию Третьего компонента Базеля II (часть IV Coглашения). Положения Второго компонента Базеля II (часть III Соглашения) раскрываются нами в данной работе, указанный компонент интегрирует в себе правила-принципы процесса надзора за кредитными организациями национальными органами (центральными банками) в странах - участницах Соглашения Базель II. Также в части III Coглашения регламентируются содержание, целевые банковские риски и особенности надзорного процесса, которые мы рассмотрели в работе. 
Часть I. Руководящие принципы рыночной дисциплины банков, необходимость своевременного и полного раскрытия банками информации о достаточности капитала

Раскрытие коммерческими банками информации является логическим следствием того, что банки подчиняются положениям Базеля II. Третий компонент этого Соглашения целиком посвящен рыночной дисциплине, что предусматривает полномочия и средства органов надзора принуждать банки раскрывать информацию. Результатом раскрытия информации становится квалификационный критерий, опираясь на который применяются те или иные методологии и признаются соответствующие банковские операции и инструменты.

Третий компонент Базеля II, посвященный рыночной дисциплине, дополняет Первый компонент - минимальные требования к капиталу коммерческого банка и Второй компонент - надзорный процесс. Базельским комитетом сформирован комплекс требований раскрытия информации, благодаря которому участники рынка банковских продуктов и услуг могут оценивать данные о капитале, степень вовлеченности банка в риски, качество процедур оценки банком рисков и в итоге получить представление о достаточности капитала данного коммерческого банка. Раскрытие информации тем более необходимо в силу того, что сам Базель II предоставляет банкам возможность опираться на собственные внутрибанковские методологии, отражающие свободу выбора при оценке уровня достаточности их капитала.

Принципиальный подход состоит в том, что руководители и члены советов директоров в каждом банке воспринимают раскрытие информации о своем банке, риски банка, управление этими рисками как звенья одной цепи и реализуют работу с ними непрерывно и в сочетании. Первый компонент Базеля II предусматривает применение банками определенных методологий и подходов для измерения рисков, что позволяет с некоторым положительным запасом рассчитывать размер капитала банка. В целом данный подход становится отправной точкой для дальнейшего корректного информирования участников рынка банковских продуктов и услуг о рисках, связанных с конкретными банками, предоставление банками данных на основе такого подхода образует механизм поэтапного и подробного раскрытия информации.

В национальных юрисдикциях стран участниц Базеля II органы банковского надзора располагают целым спектром полномочий, включая установление требований раскрытия банками информации. Подчинение банков рыночной дисциплине является основой формирования банковской сферы с низкими уровнями рисков и высоким уровнем надежности участников рынка банковских продуктов и услуг. Необходимость обеспечения безопасного и надежного функционирования этого рынка легитимирует требование органов надзора к банкам о раскрытии информации. В то же время органы надзора вправе требовать от коммерческих банков предоставления сведений в рамках обязательной периодической отчетности, которую банки подают априори. Необходимую часть информации из обязательной отчетности банков органы надзора могут направлять к опубликованию, что обеспечит ее раскрытие.

Существуют механизмы принуждения банков к исполнению указанных выше требований. В зависимости от особенностей национального банковского законодательства от страны к стране такие механизмы могут отличаться и ужесточаться, предполагая движение от диалога с руководителями банка с переходом к письменным замечаниям до завершения на уровне финансовых санкций, применяемых к недисциплинированному банку. Применение инструмента воздействия обусловлено степенью значительности недостатков, допущенных при раскрытии банком информации.

Наряду с показанными общими мерами могут применяться и специальные прямые санкции. Например, в соответствии с Первым компонентом Базеля II раскрытие информации обязательно и является квалификационным критерием для вычисления банком более низкого весового коэффициента риска, а также для применения банком конкретной методологии оценки рисков. В том случае, если банком не выполнено требование о рас- 


\section{МЕЖДУНАРОДНОЕ ПРАВО И СРАВНИТЕЛЬНОЕ ПРАВОВЕДЕНИЕ}

крытии информации, это влечет в отношении его прямую санкцию - отказ применения более низкого весового коэффициента риска, отказ в разрешении применять ту или иную методологию оценки рисков.

\section{Часть II. Требования раскрытия банками информации во взаимосвязи с их финансовой отчетностью}

Базельский комитет исходит из того, что раскрытие банками информации не отменяет и не заменяет существующие требования стандартов бухгалтерской отчетности. Требования бухгалтерского учета существенно шире Третьего компонента Базеля II, преимущественно нацеленного на выявление факта достаточности капитала банка через раскрытие им информации. Базельский комитет считает обязательным взаимодействие с национальными и международными организациями, регулирующими стандарты бухгалтерского учета и отчетности, потому что, будучи в конструктивном контакте с ними, Комитет получает возможность совершенствовать положения Третьего компонента Базеля II о рыночной дисциплине коммерческих банков.

Руководители банков на свое усмотрение определяют средства и места для раскрытия информации. Например, для выполнения требований Третьего компонента Базеля II банк может опираться на релевантную информацию из документов бухгалтерского учета, а также из документов, формируемых при прохождении листинга на фондовой бирже. Допускается раскрытие информации на официальном интернет-сайте банка, в публичной части нормативных отчетов, которые банк представляет в надзорный орган в соответствии с требованиями национального банковского законодательства с отдельным указанием на то, где можно найти дополнительные, отсутствующие в финансовой отчетности сведения. Приоритетным подходом здесь является концентрация раскрываемой информации в одном легкодоступном месте.

Раскрываемая банком согласно Третьему компоненту Базеля II информация не нуждается в проверке и заверении внешним аудитором, вместе с тем этого вправе потребовать регулятивные органы в сфере стандар- тов бухгалтерского учета, в сфере рынка ценных бумаг, в иных сферах финансового рынка. В том случае, если банк публикует, например, на своем интернет-сайте материал без аудиторского подтверждения в виде раздела сайта или самостоятельного исследования, в качестве самостоятельно подготовленного отчета, руководство данного банка обязано обеспечить подтверждение такой информации в соответствии с установленным алгоритмом ее раскрытия.

Пользователь информации о банке, принимающий решение или проводящий оценку, полагается именно на предоставленные банком в данный момент сведения. Если упущение каких-то данных, их неправильное изложение реально влияют на оценку пользователя и принятие им решения, такая информация считается существенной. Здесь можно отметить, что изложенное определение существенности информации согласуется с Международными стандартами бухгалтерского учета, а также тот факт, что Базельский комитет устанавливает проверку пользователем и необходимость экспертной оценки самим пользователем того, считать ли информацию существенной. В этой связи очевидно, что мнение самого пользователя - важнейший ориентир, при этом Базельский комитет не закрепляет порогов раскрытия информации, поскольку гипотетически ими можно манипулировать, но в то же время их весьма трудно установить.

Раскрываемая крупными международными банками (включая их дочерние организации) согласно Третьему компоненту Базеля II информация должна публиковаться ежеквартально и отражать сведения: 1) о капитале первого уровня; 2) общих коэффициентах достаточности капитала; 3 ) совокупном капитале, совокупном регулятивном капитале. В целом информация, раскрываемая по Третьему компоненту Базеля II, публикуется банками каждое полугодие. Качественную информацию коммерческие банки публикуют ежегодно, давая определения используемой терминологии, сообщая общие сведения о целях и политике банка по управлению рисками, о системе отчетности. При публикации существенной информации банк обязан соблюдать периодичность, установленную национальным банковским законодательством страны пре- 
M.В. Гончарова. Международное соглашение Базель II: общие положения орыночной дисциплине

бывания, более подробные сведения об этом можно получить в учебнике «Право Европейского Союза» [1].

Различается собственная информация банка (сведения о продуктах, услугах) - такая информация, которая может финансовые вложения в развертывание этих продуктов и услуг сделать менее ценными и далее снизить конкурентоспособность данного банка, если такую информацию сообщить конкурирующим банкам. Существует конфиденциальная информация о клиентской базе, она накапливается и охраняется на основе действующего законодательства и юридического соглашения сторон. Также к конфиденциальной информации относятся внутренние управленческие системы, методы, приемы проведения операций банка, методологии оценки тех или иных параметров, финансовых, экономических данных. Третий компонент Базеля II уравновешивает и нейтрализует возможные дисбалансы между требованиями раскрытия информации и собственной и конфиденциальной информацией. Предусмотрено, например, если банк вследствие раскрытия каких-то элементов собственной и (или) конфиденциальной информации может нанести себе материальный либо репутационный ущерб, то разрешается раскрывать не именно эти данные, а более общие сведения, дополняя их объяснением, почему требование не выполнено полностью в установленном виде.

\section{Результаты}

Практически Третий компонен т Базеля II содержит требования к раскрытию банками информации, которые Соглашением закреплены в виде 13 таблиц в параграфаx 822-826. Каждая таблица предусматривает конкретные позиции, отражающие раскрытие банком определенной качественной информации и указанной в таблице количественной информации.

Требования раскрытия банками информации в рамках Третьего компонента Базеля II дифференцированы по таблицам следующим образом:

1) сфера применения требований;

2) сведения по структуре капитала;

3) информация по достаточности капитала;
4) сведения о кредитном риске: общее раскрытие информации всеми банками стран - участниц Базеля II;

5) информация о кредитном риске: раскрытие информации по портфелям (стандартизированный подход), весовые коэффициенты риска органа банковского надзора (подходы IRB);

6) сведения о кредитном риске: раскрытие информации по портфелям (подходы IRB);

7) информация о снижении кредитного риска (стандартизированный и подходы IRB);

8) сведения о секъюритизации активов (стандартизированный и подходы IRB);

9) информация о рыночном риске: раскрытие информации банками (стандартизированный подход);

10) сведения о рыночном риске: раскрытие информации банками по торговым портфелям (подход внутренних моделей IMA);

11) информация об операционном риске (только качественная информация);

12) сведения об акциях (долевых инструментах): раскрытие банками информации по конкретным позициям в банковском портфеле;

13) информация о процентном риске в банковском портфеле (метод измерения IRRBB).

\section{Выводы}

Соглашение Базель II «Международная конвергенция измерения капитала и стандартов капитала: новые подходы» в параграфах 808826 регламентирует положения, соблюдение которых банками должно обеспечивать стабильность на рынке банковских продуктов и услуг, надежность его участников, своевременные и в полном объеме расчеты между ними. Третий компонент Базеля II, посвященный рыночной дисциплине, дополняет Первый компонент минимальные требования к капиталу коммерческого банка и Второй компонент - надзорный процесс. Базельским комитетом сформирован комплекс требований раскрытия информации, благодаря которому участники рынка банковских продуктов и услуг могут оценивать данные о капитале банка, степень вовлеченности банка в риски, качество процедур оценки банком рисков и в итоге получить адекватное представление о достаточности капитала данного коммерческого банка. 


\section{МЕЖДУНАРОДНОЕ ПРАВО И СРАВНИТЕЛЬНОЕ ПРАВОВЕДЕНИЕ}

\section{СПИСОК ЛИТЕРАТУРЫ}

1. Право Европейского Союза / под ред. А. Х. Абашидзе, А. О. Иншаковой. - М. : Юрайт, 2016. $-482 \mathrm{c}$.

2. International Convergence of Capital Measurement and Capital Standards: a Revised Framework. - Electronic text data. - Mode of access: http://www.bis.org/publ/bcbs118.htm. - Title from screen.
REFERENCES

1. Abashidze A.Kh., Inshakova A.O., eds. Pravo Evropeyskogo Soyuza [European Union Law]. Moscow, Yurayt Publ., 2016. 482 p.

2. International Convergence of Capital Measurement and Capital Standards: a Revised Framework. URL: http://www.bis.org/publ/ bcbs118.htm.

\section{Information about the Author}

Marina V. Goncharova, Doctor of Economic Sciences, Professor, Department of Economics and Management, Plekhanov Russian State University of Economics (Volgograd Branch), VolgoDonskaya St., 11, 400066 Volgograd, Russian Federation, goncharova.sofia@gmail.com.

\section{Информация об авторе}

Марина Вячеславовна Гончарова, доктор экономических наук, профессор кафедры экономики и менеджмента, Российский государственный экономический университет им. Г.В. Плеханова (Волгоградский филиал), ул. Волго-Донская, 11, 400066 г. Волгоград, Российская Федерация, goncharova.sofia@gmail.com. 